\title{
Viewing and attention in children
}

Clange-Küttner (clangekuettner@tondonmet.ac.uk; clangekuettner@uni-bremen.de) 1.2

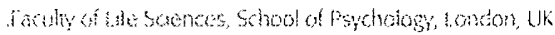

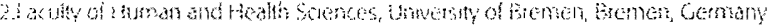

\section{Keywords}

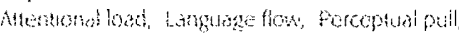

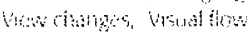

\section{Correspondence}

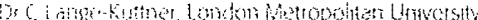

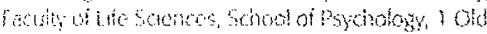

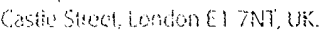

B.t. $+4.207 .320 \cdot 1075$

as: $44-20 \%-20+1236$

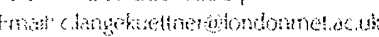

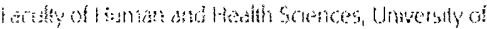

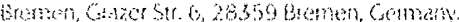

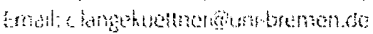
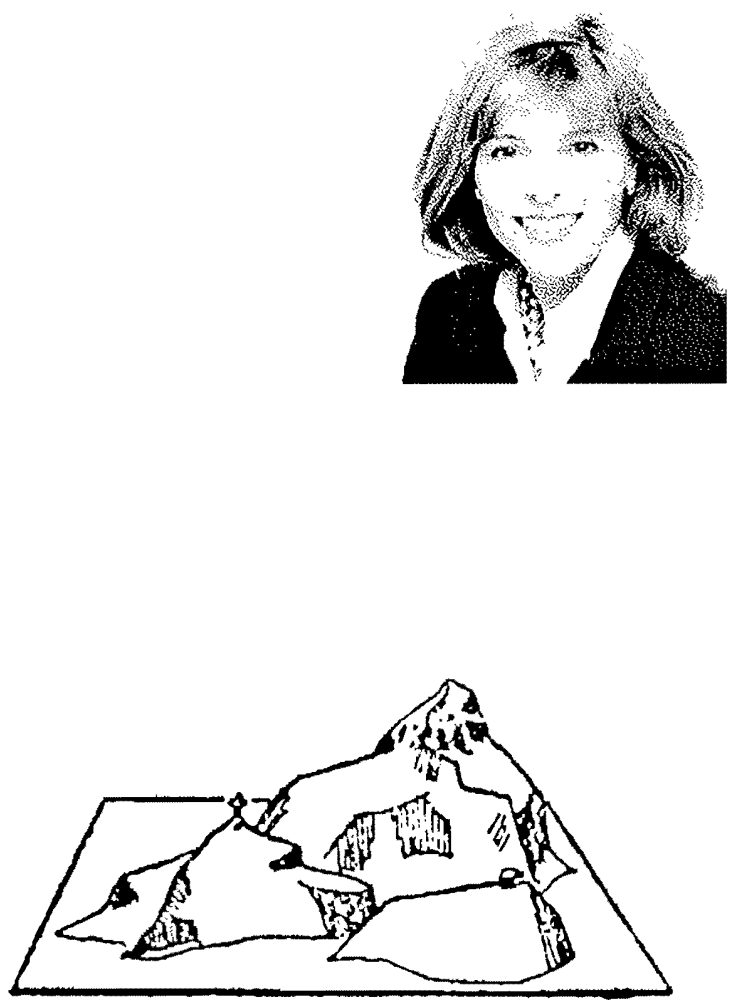
also a new and exciting research paradigma where two traditions within developmental psychology have been linked, i.e. vicwing and attention. In my commentary, 1 am describing the backgromd to children's viewing of mulliple visual scenes with regard to attentional load. I begin with a brief revicu of the carliest systemalic research on view process. ing in children, the Three Momatains task, and continue with the possible cognitive and neuropsychological background behind view processing.

Children's vicwing of visual secnes was part of the Swiss psychologists Piaget's and Inhelder's research on the development of spatial reasoning (2). Their Three Mountains Task had become a well-researched paradigm in the 1980s and is part of nearly every developmental psychology textbook. Children were asked to decide from the four views of the Three Mountains aray, which would be the one of the

Inated commentary for Cooper NR at al. Conditioning attentienal skills: examining the offects of the pace of teterision editing on chit. dren's aflemion. c

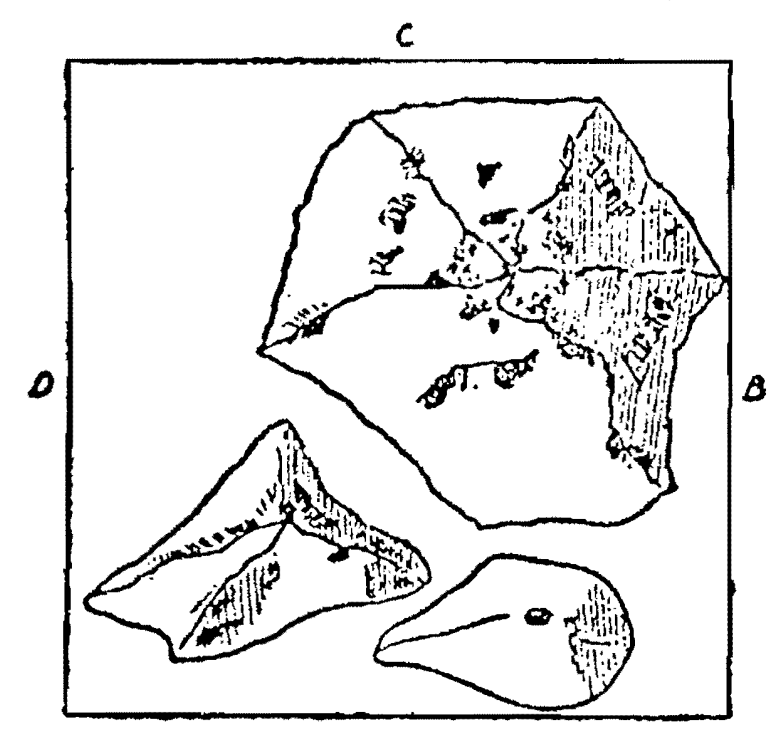

$A$ 
experimenter, i.e they were tested whether they could idenlify the perspective of somebody else (Fig. 1).

Mosi children could do this only at about age nine, with the advent of operational thought (executive skills). Before, they would often select their own perspective instead. Now adays, we could call this perseveration, but then it was called cogeentrism. Only at about age eleven did children show the same perfomance level as undergraduate students (3).

Earlier age thresholds could be found when geometrically regular blocks, rather natual objects like mountains with an irregular contour were used and it was revealed that also the overlap of the mountains was posing a difficult problem (4). An information processing perspective was proposed very early by Rosser (5) who sorted the task demands such as number of vicws and recognition ves. reproduction as response into some sort of a logical sequence. She stated with great foresight that when the task is beyond the representational and conceptual abilitics of the young child, they behave egocentrically cither because the internal relationships are most salient, or because they do not know what to do: (Rosser, 1983, p. 666). In other words, the own-view perspective is just the most familiar, so they may fall back on what they know. Perseverative responses in the most difficult task, requiring children to reconsuluet the view from readymade object shapes, oceured in $56 \%$ of the 4-year olds. 480 of the 6-year olds and still in 39 of of the 8 -year olds, ie, all these children were constructing their own view instead of the other's view.

A recent study of myself (6) used a series of four views of spatial systems into which childen had to draw figures playing a ball game. Children initially do not draw views at all, but only single objects without a spatial context. Hence, the ready-made views presupplemented their objects with a surrounding. Most 7-yearold children were drawing a habitual figure size and did not reduce size in perspective systems, but some benefited from the perceptual pull created by gradually emerging depth in one of the series without actually being aware of it. However, a landom sequence of these views where depth would wol gradually unfold did not have the same effect until 2 years later. Hence, the experience of multiple views could have an impact on 7 -year olds when their secutence corresponded to the perceptual How. This underpins the finding of Cooper ef al. that the experience of a higher amoun of views had a beneficial effect on children's attentional skills.

So if the experience of multiple views is beneficial, why would children return to their own view when their information processing capacity was challenged in the Three Mountains Task? lesponse perseveration is an imporlant problem, and could be demonstrated already in inlancy in another well-researched piagetian spatial task the $A$-not-B scarch task (7-10). Perseveration consists of a dysfunctional 'inhibition of return' which nomally favours new locations and inhibits oricnting lowards visual locations that have been previously attended (11,12). Lange-Küitmer (9) suggested that this is a return to the familiar object still bound to its original place, a relation whel would have needed dissociation before an objectnewplice unit could be constructed. However, individual object-place units lose their power as soon as multiple objects are bound into larger, common regions $(13,16)$. Perseverative responses in spatial tasks are also a problem in children with attention deficit hyperactivity disorder (ADHD) $(15,16)$.

perserveration because of limited attentional resourees can also occur in adult stroke patents with right hemi. sphere brain injury (17). They may show perserverative errors in tasks such as line cancellation, where in an array of lines, they have a tendency to return to and re-mark tar. gets that they had already cancelled $(18,19)$. This persevera. tion is often coupled with a visual neglect, where itoms on the left can become entirely ignored, yet simultaneously their presence leads to inereased perseveration in the right visual field, especially when these objects were similat to the targets (20). The more stimuli (competing choices), the higher the attentiomal load, the stronger the visual neglect $(21,22)$. Furthermore, nomal children when under pressure (23), and children with ADHD show similar behaviour (24). This suggests that real or perceived attentional load activates an innate bias to the right side in visual attention (25). The attemional task which Cooper at at. used for testing (26) did in lact test just this, orientation to the left or right spatial lield, i.e is the fish looking to the left or right side and do thave to press the left or right button respectively to feed it?

Unlike in carlier Posner paradigms $(27,28)$, where the spatial cues were left and right to the target, in the Attention Network Test (ANT) the different sorts of spatial cues were not really giving any hints about the leftright feeding: direction, as they were above and below cues along a verti. cal axis. Hence, they were just warning cues about the upcoming of the next trat to test alertness, not tapping into the innate right-side bias, which emerges under pressure. Yet, the most pronounced result in the Cooper et al. study periained to the variable 'orienting' which involved picking up a helplul spatial cue on where-10-10ok-next, with 4-yeat olds in the last-changing views condition and the 6-year olds in the slow-changing views condition benefiting most in terms of faster reaction times fi.c. negative values indicating a gain; (1)]. In contrast, 'alerting' which involved widening the visual field of the children by attracting thein attention to the entire up-down expanse (double cue) was most helpful for 4year olds who showed a gain in the fewer-views condition. The effect of congruent vs. incongru ent fish spatial context did not vary in the two conditions.

In the Cooper et al. study, in the condition with more views, a new view appeared relatively regularly affer two complete sentences of the speaker. Hence, if one supposes that children exerted more focused attention in this condition while at the same time experiencing more spatial information about the same object, this would correspond to the Three Mountains task with one object, but multiple views, a relatively optimal condition. Hence, the beneficial effect on cue pick-up in the youngest age group and increase of accuracy across age groups in the visual atten. tion test thereafter is very platusible. In contrast, in the 
fewer-views condition, children experienced long passages of read-aloud text, which would have drawn their attention and imagination to the actual storyline, while the fewer vicws would have provided relatively less incentive to increase the alertness of the vistad atiention system. 'That 6-year' olds benetited of where-fo-kok cues nuore in this condition was probably due to the effect that they would have had the ambition to do both, lining up the story and actively exploring the spatial context during the film, which would have been more conducive to do in the 'slow' condition as the language flow of the picture book story appeared more continuous. A shor memory lest at the end of the session would make it possible to test this idea in an easy way.

In short, the Cooper et al. study surely needs further rescarch, the most urgent being that children would need to be assessed on the ANT before and after the fim intervention, so that an attention bascline would be available. Children ustally conce into school with large individual differences in terms of reaction times, but standard deviations become smaller with age. However, given the many trials (24 practice trals and 48 experimental trals). we can be reasonably contident that individual differences in baseline specel may have dissipated during leaming, while the viewing experience was a valid and reliable treatment in the current study.

\section{References}

1. Cooper $N$, Uther $C$, Pellifer J, Stok F. Conditioning attentional skills: Examining the effects of the pace of television editing on children's attention. Acta Pacdiatr 2009; 98: 1651-5.

2. Piaget J, Inheter B. The child's conception of space. London Routledge and Kegan Paul, 1956

3. Gxesh SM, Suber FC. Vistal perspective-laking skills in children. Child luen 1985; 56:120:4-13.

4. Liben LS, Belknap B. Inellectual realism: Implications for investigations of perceptual perspective taking in young children. Child bo 1981; 52:921-4.

5. Rosser RA. The emergence of spatial persective taking. Child Do: $1983 ; 54: 660 \cdots 8$.

6. Lange Kütner C. Habitual size and projective size: The logic of spathat systems in children's drawings. Dov Psychol 2009; 913-27.

7. Munakala Y. hutant perseveration and implications for ohject permanenee theorics: $\triangle$ PDP model of the AB lask. Dew SC $1998: 1: 161-84$

8. Munakata Y. Juant perseveration: Rellsinking data, theory, and the role of modelling. Der Soi 1998: 1: 205-11.

9. Limge-külner $C$. When one is really (wo: Switching from whicet o place memory in the A-Not-B search task Lurop) Dew Sci $2008 ; 2: 370-83$.

10. Schutte AR, SpencerJP. Gencradizing the dynamic field theory of the A-not-B error beyond infancy: 'Thee-year-olds' delayand experience dependent heation memory biases. Child beo $2002 ; 75: 577-404$.
11. Posner MI, Rafal RD, Chone LS, Vaughan ]. Inhibition of retum: Neual basis and function. Cogh Nemopsychol 1985;2: $211-28$.

12. Posner M1, Rothban MK, Thomas 'Thrapp l., Lang PI Simons RF, Balaban MT. Functions of ortenting in early infancy. Altention and orienting: Sensory and motivational processes. Mahwal, NJ: Lawrence Erlbaum Asseciates Publishers. 1997; 327-45.

13. Lange-Kintner C Drawing boundaries: From individual to common region. The development of spatial region attribution in children. Br/ Dea Psychol 2006,24:419-27.

14. Lange-Küuner $C$. Explizite Onte: Selbstproduriene und vorgefundene Erieichterungen beim Oresgedächtnis von Kindem. 50 . Trigung experinenall arbeitender Psychologen (TENP). Narburg, 2008

15. Wilding JM, Munir F, Comish $K$. The nature of attentional dit. ferences between groups of chithen differentated by toacher ratings of atention and hyperativity. br / Pychol 2001: 92: $357-71$.

16. Wilding M Aftentional diffeulties in children: Weakness in exceutive functioning or problens in coping wh difficult tasks. Br / Psychol 2005:94:427-36.

17. Robertson 1H. Digit span and visuat neglect: a puzzling relationship. Newopsychologia 1990: $28: 217-22$.

18. Kobertson H. The relationship between lateralized and nom lateralized atcentional deficis in unilateral neglect. $m$ : Robertson IH, Narshall JC. editors Lnilateral neglect: clincal and experimental studies. Hove: UK, EHHatum, 1993 $257-75$.

19. Mamnin SK, Mort Df, Hodgson TL, Driver /, Kennard C, Hus ain M. Revisiting previously searched locations in visual neglect role of right parietal and frontal lesions in misiduging old locations as new. I Cogn Neurosci 2005; 17 : 340-54.

20. Manly T. Woldt K, Watson P, Warburton E. Is motor perseveration in unilateral negled 'driven' by the presence of neglected left-sided stimuli? Nearopsychologia 2002: 40: 1794-803.

21. Rajpscak SZ, Verfaelhe M. Flee S, Heiman KM. Selective atlention in lemispatial neglect. Arch Neurol 1989; 46: 172-8.

22. Kaplan RF, Verlaellie M, Meadows ME, Captan LR, Peasin MS. De Wiut 0 . Clanging aftentional demands in left henispatial neglect. Arch Neurol 1991; 48: 1265-6.

23. Manly T, Comish K, Gram C, Dobler V, Hollis C. Examining the relationship between rightward visuo-spatal bias and poor attention within the nomal child population using a brief screming task. (Child Psychol Psychiat 2005; $46: 1537$ 44.

24. George M, Dobler V, Nicholls E, Manly T. Spatial awareness, alemess, and ADHD: The re-cmegenec of unilaterat negled with time-on-lask. Brain Cogn 2005:57:26.1-75

25. Lange-Kümer $\mathrm{C}$ Crichtom MT. Change of spatial field elfeces in 16-10 20-week-old intants. Brain Cogn 1999; 39: 75-92.

26. Fan ], Mecandliss BD, Sommer 'I, Raz A, Posner MI. Testins the efficiency and independence of attentional neworks. J Cogn Nerrosci $2002 ; 14: 340-7$

23. Posner MI. Orienting of attention. Q I Exp Psychol 1980, 32 $3-25$

28. Posner MI Rogers MG, Estes Wh. Chrononeric analysis of abstraction and recognition. Handbook of learning \& cognitive processes: V. Human infomation. Oxford England bawrence Erbatm, 1978; $143-88$. 